\title{
The Effect of Nutritional Education Program on Mitigating Trauma Disorder among Kindergarten Children during COVID19 Pandemic
}

\begin{abstract}
Manar S. Amine ${ }^{1 *}$ and Sara A. Sayed Ahmed ${ }^{2 *}$
Abstract: This study was performed to measure the effect of nutritional knowledge education courses include (23) sessions on mitigating the effects of trauma disorder among kindergarten children through the COVID19 pandemic. The study sample included kindergarten children (5-7 years old) and their Mothers. Three questionnaires were used to assess nutritional knowledge. Also, trauma symptoms during the COVID19 pandemic were identified by using the experimental method. Data indicated that the positive effect of the nutritional education program sessions on reducing the symptoms of children's trauma disorder. Also, statistically significant differences between the mean scores of the children in the experimental group on the pre-and post-application of the questionnaire of traumatic disorder during the COVID19 pandemic were recorded. In conclusion, the present study showed that mothers canpass awareness to their young children about healthy foods which can help to fight against the COVID19 pandemic through improving their immune system. We recommended paying more attention to abnormal psychological behaviors in children by finding out their causes and trying to find solutions that may contribute to preventing their emergence in children.
\end{abstract}

Keywords: COVID19 pandemic, nutritional Knowledge, questionnaire survey, demographic, severity of trauma symptoms, kindergarten children.

${ }^{1}$ Department of Psychological science, Faculty of Early Childhood Education' and ${ }^{2}$ Department of Home Economics, Faculty of Specific Education, Port Said University,Port Said, Egypt.

* Corresponding author: $\underline{\mathrm{dr} \_ \text {manar@kind.psu.edu.eg }}$ 


\section{أثر برنامج التثقيف الذّائي في تذفيف اضطراب ما بعد الصدمة}

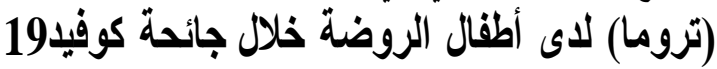

سارة أحمد سيد أحمد² ، منار شحاتة محمود أمين 1

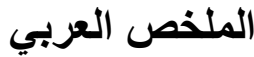

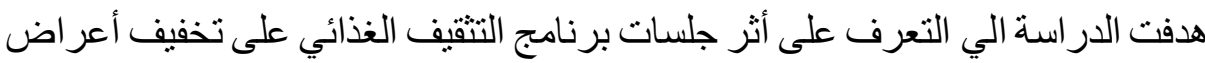

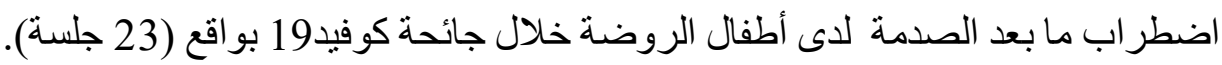

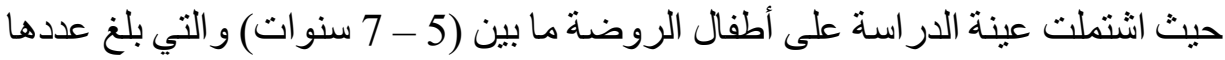
(60 طفل وأمهاتهم) حيث استخدم الباحثتان المنهج شبه التجريبي (المقارنة التهن بين نتائج

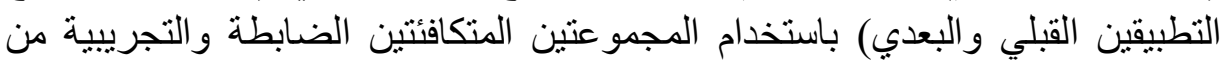
خلال تطبيق ثلاثة استبيانات اثنان منهما لتقييم المعرفة التغذوية التخدية عند الأمهات و الأطفال

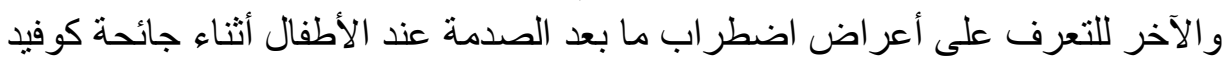

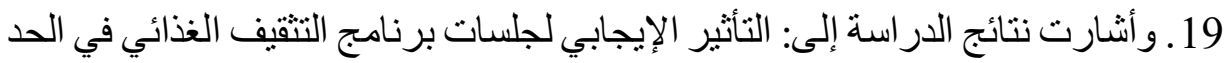

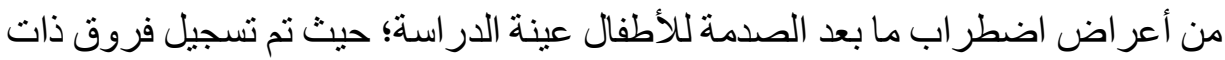
دلالة إحصائية بين متوسطات درجات الأطفال في المجموعة التجريبية على التطبيق

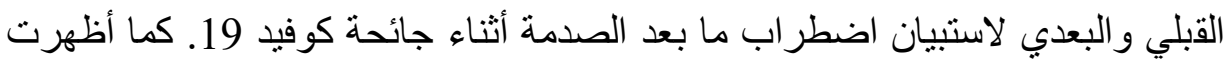

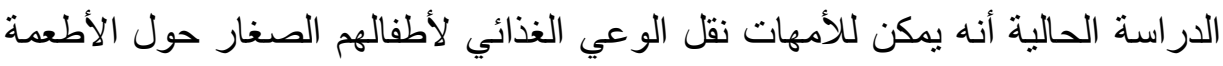

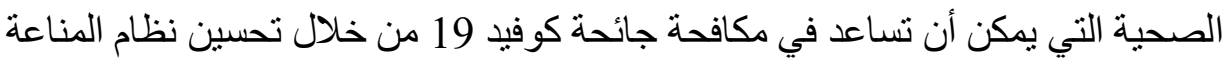

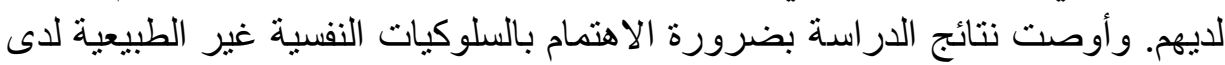

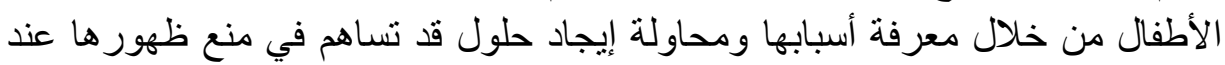
الأطفال.

الكلمات المفتاحية: جائحة COVID19 ، التتقيف الغذائي ، استبيان ، الديمو غر افية ،

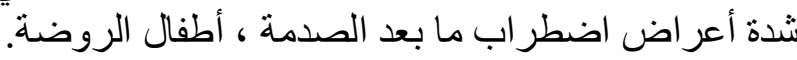
1مدرس بقسم العلوم النفسية ، كلية التربية للطفولة المبكرة ، جامعة بورسعيد . 2مدرس بقسم الاقتصاد المنزلي ( تغذية وعلوم الأطعمة) ، كلية التربية النوعية، جامعة 


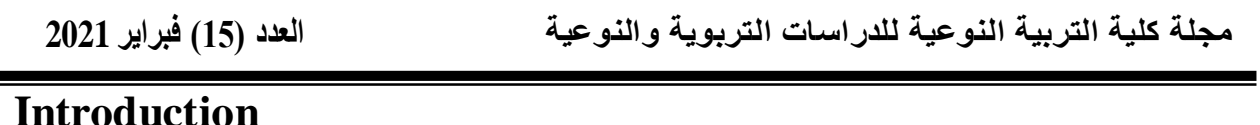

The most urgent public health issue of the $21^{\text {st }}$ century thus far is the global COVID19 pandemic caused by a novel COVID19 strain estimated to have caused over 1.5 million deaths in 2020 (Johns Hopkins, 2020). The World Health Organization (WHO) declared it as a pandemic on 11th March 2020 due to its serious andrapid spread (WHO, 2020). Four months after its emergence, the virus had spread to many countries and officially infected over 25 million people and claimed over 865,644 lives on 2nd September 2020 (World meter Statistics, 2020). Egypt was ranked 62nd in the number of people infected with the emerging COVID19, out of 215 regions and countries around the world (Health, 2020). Frist case of COVID19 in Egypt infections was discovered on February 14, 2020. Then on March 13th, 2020, the Prime Minister's directive to suspend studies in all levels of education as well as all other life activities for different periods as a precautionary and preventive measure to prevent the spread of the Coronavirus in the country. Also, maintaining personal hygiene instructions from washing hands and all general hygiene requirements (The Arab Republic of Egypt., 2020). Since February 14, 2020, when the $1^{\text {st }}$ first case of COVID19 infections appeared, the cases numbers were increased to exceed 7000 cases by May 2020 with a mortality rate of $6.4 \%$ (Health, 2020). Since there is still no specific cure or effective vaccine available for COVID19, the main means of minimizing disease, death, and other pandemic costs are behavior. This behavior includes social distancing measures such as limiting non-essential trips outside of the home and maintaining adequate social distance (6 feet or greater) from others in public settings (Centers for Disease Control and Prevention, 2020).

The novel COVID19 pandemic has led to unprecedented disruptions and stress in the lives of children and families (Gur-witch et al., 2020). These upheavals include new terms used worldwide, such as "quarantine", "stay home", "social distance", "individual 


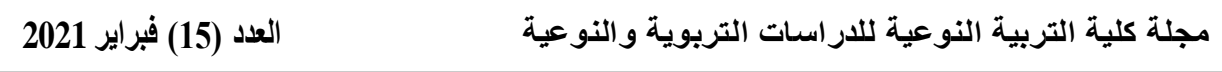
responsibility", "distance education or examination", "social isolation". These latest data inevitably have a psychological impact on many people, especially young people (Konstantopoulou et al., 2020).

Also, this pandemic places on young children a wide variety of stressors, including their invisibility, uncertain period, risk of infection, anger and boredom, poor information, lack of face-toface interaction with their families, schoolmates, andfriends, lack of personal room at a home and family financial loss. These massive changes would possibly have difficult and lifelong effects on children (Wang et al., 2020). It is predicted that the pandemic will cause post-traumatic, anxiety, and depression disorders. Some groups, like children, have more susceptibility to havinglong-term consequences in mental health (de Miranda et al., 2020). Trauma has been defined as events that overwhelm a person's ability to adapt to life, leading to strong negative emotions that are associated with the degree of experienced or witnessed threat to self (Phelps and Sperry ,2020).

Trauma can directly disrupt a child's emotional regulation. Children who experience trauma are more consistently aroused and thus unable to appropriately monitor their behaviors, which can lead them to be more impulsive and aggressive. In essence, traumatic experiences challenge the regulatory system; thus, people who experience PTSD will have emotion management difficulties. Many psychopathologies, however, are often seen, at least in part, as emotion management issues, including depression and anxiety, borderline personality disorder, and eating disorders (PatHorenczyk et al., 2015). To ensure adequate and timely intervention, it is essential to understand the psychological effect of such exposure and the prevalence of PTSD in this population (Wool- gar, 2020). Besides the psychological effects of the COVID19 lockdown on kids and adolescents, some studies reportable enlarged rates of stress in mothers. The perceived lockup 
difficulties will affect parental stress that successively might affect the psychological well-being of kids (Dalton $\boldsymbol{e t}$ al., 2020 and Spinelli et al., 2020). Also, Spinelli et al., (2020) found that mothers with more trouble in quarantine had more tension, which in turn in-creased children's difficulties in emotion and conduct. Furthermore, Orgilés et al., (2020) found a correlation between perceived difficulties in family coexistence in quarantine, increased levels of maternal stress, and recorded parental emotional problems in children. In recent years, there has been considerable interest in the relationship between diet and mental health. Indeed, epidemiological research has shown that adherence to balanced or Mediterranean dietary habits is associated with a decreased risk of depression including high consumption of fruits, vegetables, nuts, and legumes; modest consumption of poultry, eggs, and milk products; and only occasional consumption of red meat (Lassale $\boldsymbol{e t}$ al., 2019). There- fore, the combination of nutrition interventions with stimulation and responsive care is necessary. Combined nutrition and psychosocial stimulation approaches can potentially work effectively together to promote protective factors and mitigate risks for poor cognitive, motor, social, and affective functioning helping children to adapt in times of adversity (Yousafzai $\boldsymbol{e t}$ al., 2013). Empirical evidence, however, indicates that the availability and accessibility of services such as food and health facilities, including location ad- vantage, are not sufficient to produce child health, such as mother's education, and in particular mother's knowledge concerning food choices, feeding, and health-seeking (Fadare et al., 2019).

The most appropriate study with which trauma symptoms is the nutrition knowledge for mothers and their children aged 3 to 6 years (Al-Majed et al., 2001). The growth time is an important stage in developing eating habits because acquired dietary patterns will continue into adulthood during the first years of life (Nikitsing $\boldsymbol{e t}$ al., 2018). This literature reviews systematically described and reviewed research exploring the link between diet and mental health 
in children and young people. At present, psychological counseling is the first-line treatment for depression. These, however, fail to reduce the burden of depression due to the lack of response of people, especially the younger population, to these medications (Perez, 2018). There was a general trend to report minor connections between diet and mental health, with the 'un- healthy' diet correlated with increased chances of mental health issues and the 'healthy' diet having the opposite effect. In the studies examining whether a healthy or unhealthy diet is correlated with depression, similar conclusions were drawn. The findings from the latest study were consistent with the finding that there was a link between unhealthy eating habits and deteriorating mental health (Khalid $\boldsymbol{e t}$ al., 2016).

On the other side, diet and lifestyle affect the development processes. These factors also shape the current behavior and future habits of a person and affect their health status not only in childhood but also in adulthood. A child's diet should be based onhealthy nutrition principles and adapted to their age-adequate energy and nutrient requirements (Zyśk et al., 2020). Despite this importance corresponding to the nutritional knowledge of mothers and their children, many kindergarten programs neglect to include a curriculum on proper and balanced nutrition for students. Although good nutrition is expected in most kindergarten programs, many children have not yet learned about healthy or unhealthy foods and what a balanced meal is. In a kindergarten program, more discussions and activities should be done around identifying healthy foods, what it means to have a balanced meal, and understanding and identifying the difference between healthy and unhealthy food in a way that is fun and engaging to fill in the lack of nutrition curriculum (Rapson et al., 2020). There is a lack of knowledge about nutritional education in the kindergarten curriculum. Such lack contributes to lasting negative health conditions and impedes children'sability to learn (Fisberg and Batista, 2020 and Amahmid et al., 2020). 
Therefore, the present study aimed to investigate the effect of nutritional knowledge education courses on mitigating trauma disorder among kindergarten children during the COVID19 pandemic.

\section{Methods Sample of the study}

The study sample consisted of 60 kindergarten children and their mothers, the children sample included 20 boys $(33.33 \%)$ and 40 girls $(66.67 \%)$. Their ages ranged from 5-7 years $(6.3 \pm 0.76)$ in Zahraa Port Fouad approved primary School, Port Said Governorate, Egypt.

\section{Study tools:}

\section{Questionnaire survey about nutritional knowledge assessing for mothers and kindergarten children}

Form A for mothers: The Arabic version of the revised general nutritional knowledge questionnaire (GNKQ-R) by Bataineh and Attlee (2020) was used. The Arabic version of GNKQ-R was adapted from the English version of the recently validated eightyeight-item GNKQ-R (Kliemann et al., 2016). The eighty-eightitem English GNKQ-R was adapted into an eighty-six-item Arabic version consisting of four sections evaluating nutritional Knowledge as follow: section 1, dietary recommendations (seventeen questions), section 2, food groups and nutrient sources (thirtysix questions); section 3, healthy food choices (twelve questions); and section 4: associations between diet-diseases and weight (twenty-one questions). The questions were in the multiple-choice for- mat, and checkmarks were used as responses. Answers were scored by assigning one point for each correct response and zero points foran incorrect response.

\section{Form A Validity and Reliability}

The eighty-six-item GNKQ-R Arabic version can be considered a reliable and valid tool for assessing NK among the young adult Arab 
population. The Arabic version was found to have good internal and external reliability, consistent with the reliability of English GNKQR. (Bataineh and Attlee 2020). The overall internal reliability of the GNKQ-R Arabic version was high (Cronbach's $\alpha=0.91$ ) and comparable to the English version (Cronbach's $\alpha=0.93$ ) (Kliemann et al., 2016) Further, the test-retest reliability of the overall NK score was high (r 0.84) in the GNKQ-R Arabic version parallel to the English one (r 0.89). Also, all sections of NK showed good internal as well as test-retest reliability (Bataineh, and Attlee, 2020).

Form B for kindergarten children (traffic light food scale) used as in Johnson, (2017) which includes 29 questions ask about go foods (Green) these are very healthy foods and drinks, slow foods (Yellow) these foods and drinks may have some fat or some sugar, and WHOA foods (Red) these foods and drinks are sugary, or high in fat. (Correction: kid takes one for the correct response and zero for the wrong response).

\section{Form B. Validity \& Reliability}

Face and content validity were determined for questions and pilot tested. Statistical analysis indicated item discrimination, with Cronbach's $\alpha$ determined to be .75 , and test-retest administration indicated a reliability coefficient of 0.83 (Johnson, 2017).

\section{Questionnaire survey about trauma symptoms}

A questionnaire survey about trauma symptoms during the COVID19 pandemic for kindergarten children prepared the researchers which include 34 Observed Behaviors as follows: mothers were asked about their children's behaviors during the COVID19 pandemic in seven domains. This Questionnaire survey was validated in the Port Said governorate. This is made up of 34 items selectedbased on a literature review of stress reactions and trauma in young children such as mentioned by Wilson and Tang (2007), Masten et al., (2008), Scheeringa et al., (2011), Feldman, 
and Vengrober, (2011), Malarbi et al., (2017), El-Khodary and Samara, (2020), Alshehri et al., (2020), Xiao et al., (2020) and Wang et al., (2020). The mothers rated the severity of each trauma reaction on a three-point scale $(3=$ Not at all, $2=$ Mild and $1=$ Severe). Also, mothers reported whether or not each stress reaction was presented before the COVID19 outbreak.

\section{Questionnaire Validity and Reliability}

Face and content validity were determined for questions and pilot tested. Statistical analysis indicated item discrimination, with Cronbach's $\alpha$ determined to be 0.79 . The split half reliability of Questionnaire scores was 0.815 . also, The internal consistency of the questionnaire calculated using and Cronbach's alpha, was $\alpha=0.86$, as follows: domain 1 , relationships (5 items) where the value of alpha $(\alpha=0.84)$; domain 2 , mental health (3 items) where the value of alpha $(\alpha=0.80)$; domain 3 , brain development (4 items) where the value of alpha $(\alpha=0.82)$; domain $4, \operatorname{cognition}(5$ items) where the value of alpha $(\alpha=0.88)$; domain 5, behaviors (6 items) where the value of alpha ( $\alpha=$ 0.90 ); domain 6 , emotions (6 items) where the value of alpha $(\alpha=0.92)$ and domain 7, physical health (5 items) where the value of alpha $(\alpha=0.89)$.

\section{Study Procedure}

The selection of the sample, grade 2 from 5-7 years old, was chosen from Zahraa Port Fouad approved primary School, PortSaid Governorate, Egypt. The study procedure could be summarized as follow:

- Assessment of nutritional knowledge for mothers using the Arabic version of GNKQ-R.

-Assessment of nutritional knowledge for children using the traffic light food scale.

-Application questionnaire survey about trauma symptoms during 
COVID19 pandemic for kindergarten children.

- Dividing the children into two groups using the experimental approach, a control group, and an experimental group, equally. The number of children in each group equals 30 boys and girls.

- Controlling the equality of the sample in terms of (the age of children - the cultural level of the mothers - the family income).

- Application nutritional education program sessions on children of the experimental group and their mothers only without exposing children of the control group.

- Assessment of the nutritional knowledge of children and their mothers - application questionnaire survey about trauma symptoms during COVID19 pandemic for kindergarten children.

\section{Statistical Analysis}

All measurements were recorded as mean \pm SD. The significance of differences was determined by $t$-test pre, post. A probability level of $P \leq 0.05$ was considered statistically significant. In Statistical analysis to test the validity of statistical hypotheses, the Statistical Package of Social Science-version 20 (SPSS 20.0) for data entry and analysiswas used.

\section{Results and Discussion Selection of the research sample}

The results showed that the distribution of the Study Sample was 60 kindergarten children and their mothers, a control group was 3050\% $($ Female $=20$ Male $=10)$, and the Experimental Group inthe same distribution.

\section{The equivalence of the sample in demographic variables and their scores in study tools in pre-application}

The researchers adjusted the equivalence of the sample in demographic variables including age (5-7 years), gender (male, female), mothers' education, and family income. Also, the children's and their mother's degrees on 
study tools in pre-application are shown in Tables (1 and 2) and Figure (1). The results showed that the first variable, children's age, ages from 5-6 to >6-7 years were ranged $58.33 \%$ to $41.67 \%$. The second variable, mothers' education, showed that the number of formal education and Primary education, secondary education, and tertiary education were recorded $0,16.67 \%$, and 83.33\%, respectively. The third variable, family income, the results showed that the 2000-3400 pounds were $5 \%$, > 34006500 pounds was $86.67 \%$, and > 6500 pounds was ranged $8.33 \%$.

The fourth variable, the sample scores on study tools in pre-application, the results showed that the mother's degrees on Questionnaire survey about Nutrition assessing Knowledge for mothers and kindergarten children in the control group were $9.33 \pm 2.80$, and in the Experimental Group was $9.00 \pm 2.70(t$ value $=0.4647, p=2.00$ and $>$ 0.05 , respectively). The children's degrees on questionnaire survey about Nutrition assessing knowledge for kindergarten children (traffic light food scale) in the control group was $5.50 \pm 2.26$, and in the Experimental Group was $5.35 \pm 2.22(t$ value $=0.2593, p=2.00$ and $>0.05$, respectively). The children's degrees on questionnaire survey about trauma symptoms during COVID19 Pandemic for kindergarten children in the control group was $50.67 \pm$ 5.18 , and in the experimental group was $52.67 \pm 3.41(t$ value $=1.7680, p=2.00$ and $>0.05$, respectively). In a similar study, Schiff $\boldsymbol{e t} \boldsymbol{a l}, \mathbf{2 0 1 7}$ found that in demographic variables, mother culture plays an important role in reducing the symptoms of trauma disorder in children. That maternal psychological distress and social support constitute the key factors in developing resiliency among young children exposed to multiple traumatic events. As maternal perceived social support is associated with lower 
levels of maternal depression, it is essential to discuss those associations with mothers to young children who are faced with political violence and other traumatic events, as well as assist mothers to approach and gain social support. Also, Assari, (2020) found that parental education and family income had statistically significant protective (negative) effects on childhood trauma, indicating children from high-income and highly educated families were exposed to a lower level of childhood trauma.

Table (1). The equivalence of the sample in demographic variables

\begin{tabular}{|c|c|c|c|c|}
\hline No. & Demographic variables & Frequency & $\begin{array}{c}\text { Relative } \\
\text { percentage }\end{array}$ & Mean \\
\hline \multirow[t]{3}{*}{1} & Age (5-7 years) & & & 5.9 \\
\hline & (5-6) years & 35 & 58.33 & \\
\hline & (> 6-7) years & 25 & 41.67 & \\
\hline \multirow[t]{5}{*}{2} & Mothers' education & & & $\begin{array}{c}\text { Tertiary } \\
\text { education }\end{array}$ \\
\hline & No formal education & 0 & 0 & \\
\hline & Primary education & 0 & 0 & \\
\hline & Secondary education & 10 & 16.67 & \\
\hline & Tertiary education & 50 & 83.33 & \\
\hline \multirow[t]{4}{*}{3} & Family income & & & 4500 \\
\hline & 2000-3400pounds & 3 & 5 & \\
\hline & $>3400-6500$ pounds & 52 & 86.67 & \\
\hline & $>$ 6500pounds & 5 & 8.33 & \\
\hline
\end{tabular}


Table (2). The equivalence of the sample in their scores on study tools in pre-application

\begin{tabular}{l|l|c|c|c}
\hline No. & $\begin{array}{l}\text { Pre-application on } \\
\text { Tools }\end{array}$ & $\begin{array}{c}\text { Control } \\
\text { Group } \\
\text { N=30 } \\
\text { Mean } \pm \text { SD }\end{array}$ & $\begin{array}{c}\text { Experimental } \\
\text { Group } \\
\text { N=30 }\end{array}$ & \multirow{2}{*}{ Mean \pm VD } \\
\cline { 2 - 4 } $\mathbf{1}$ & $\begin{array}{l}\text { Questionnaire survey about } \\
\text { Nutrition assessing } \\
\text { Knowledge for mothers. }\end{array}$ & $9.33 \pm 2.80$ & $9.00 \pm 2.70$ & $0.4647^{*}$ \\
\hline $\mathbf{2}$ & $\begin{array}{l}\text { Questionnaire survey about } \\
\text { Nutrition assessing } \\
\text { Knowledge for } \\
\text { kindergarten children } \\
\text { (traffic light food scale) }\end{array}$ & $5.50 \pm 2.26$ & $5.35 \pm 2.22$ & $0.2593^{*}$ \\
\hline $\mathbf{3}$ & $\begin{array}{l}\text { Questionnaire survey about } \\
\text { Trauma Symptomsduring } \\
\text { COVID19 Pandemic for } \\
\text { kindergarten children }\end{array}$ & $50.67 \pm 5.18$ & $52.67 \pm 3.41$ & $1.7680^{*}$ \\
\hline$*<0.05$. & & & \\
\hline
\end{tabular}

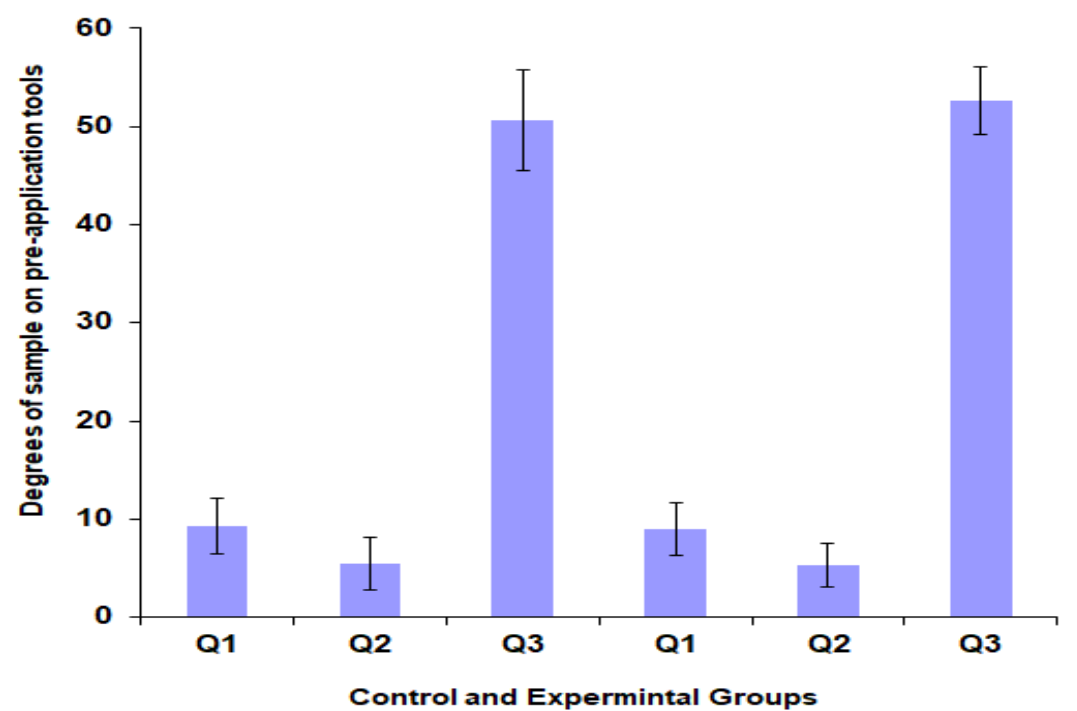

Figure 1. The equivalence of the sample in their scores (Mean $\pm \mathrm{SD}$ ) on study tools in pre-application 


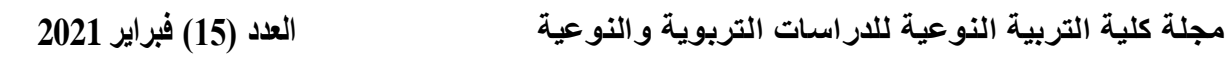

However, there have been statistically important relations between race and ethnicity with parenting and household income about trauma exposure, which show less protective impacts on the reduction of trauma exposure from parental and family education. Furthermore, Jacka, (2013) reported that children with a low level of a postnatal healthy diet also had higher levels of both internalizing and externalizing problems. Early dietary exposures were separately linked to the potential for behavioral and emotional issues in children.

Differences between the mean scores of mothers and their children in" control\& experimental "groups on Questionnaire survey about Nutrition assessing Knowledge in post application

The total score of Parents post-application on the questionnaire survey about nutrition assessing knowledge for mothers is shown in Table (3) and Figure (2). The results showed that there are statistically significant differences between the mean scores of mothers of the control group $(9.33 \pm 2.80)$ and the experimental group $(49.83 \pm 2.59)$ on the questionnaire survey about nutrition assessing knowledge for mothers in the post-application, as indicated by the mean total scores of ( $t$ Value $=58.23, p<0$. 01). Also, the total score of kindergarten children in post-application on the questionnaire survey about nutrition assessing knowledge for kindergarten children (traffic light food scale) in Table (4) and Figure (5). The results showed that there are statistically significant differences between the mean scores of kindergarten children of the control group $(5.50 \pm 2.26)$ and the experimental group (25.50 \pm 0.97) on the Questionnaire survey about Nutrition assessing Knowledge for kindergarten children (traffic light food scale) in the post-application, as indicated by the mean total scores of ( $t$ Value $=44.59, p<0.01)$. Such data attribute these statistical differences in the dimensional scores of the post-application in the control and 
experimental groups due to their conviction of the relationship between nutritional awareness and their cognitive achievement on the most important issues of healthy nutrition and the low percentage of their anxiety about infection with the COVID19, which is equally positively reflected in the trauma disorder in their children.

On the other side, using a variety of educational materials, including pictures, videos, acting, and playing, helped children learn more about healthy nutrition with various topics such as exploring the food groups - fruits (Focus on whole fruits), vegetables (Vary your veggies), grains (Make half your grain whole grain), protein (vary your prion routine ), dairy (Move to low fat or fat-free dairy milk or yogurt), how Nutrition can help to fight against COVID19 Pandemic and improve our immune system, vitamin C (Benefits \& food sources), vitamin D (Benefits \& food sources), zinc (Benefits $\&$ food sources), omega 3 (Benefits \& food sources), selenium (Benefits \& food sources), iron (Benefits \& food sources) - vitamin E (Benefits \& food sources ), B-complex vitamins (Benefits \& food sources), vitamin A (Benefits \& food sources), Probiotic (Benefits \& food sources )- Less sugar and salt - water and body, Food to avoid and food to enjoy, exercise, eat healthily and get plenty of sleep. In a similar study, Gower et al., (2010) found the content validity of sessions, as indicated by expert peer ratings. Test-retest reliability correlations were found to be significant for the overall survey $(r=0.54 ; p<0.01)$ and for all subscales: food groups, healthful foods, and food functions $(r=0.51,0.65$, and 0.49 , respectively, $p<0.01)$.

Nutrition knowledge was assessed upon program completion with paired-samples t-tests. Students from the intervention group demonstrated improvement in nutrition knowledge (12.2 \pm 1.9 to $13.5 \pm 1.6 ; p<0.01$ ), while scores for the control group remained unchanged. The difference in total scores from pre- to postintervention between the two groups was significant $(p<0.01)$. Also, the study results imply that the Fit Kids 'or' Healthy Kids intervention promoted gains in nutrition knowledge. 
Overall, the computer survey shows promise as an appealing medium for assessing nutrition knowledge in children. Also, Friel $\boldsymbol{e t}$ al., (1999) studied the evaluation of the nutrition education at primary school (NEAPS) program results showed that Significant differences were found in the intervention children's behavior and preference levels after the NEAPS program $(p<0.01$ in both sections). Knowledge levels were very high at baseline and though some individual items improved, average change overall was not significant. Rural children appeared to benefit more in behavior and preferences from the program $(p<0.01)$. The NEAPS program appeared to be less effective in pupils in disadvantaged areas $(p<$ 0.01 for each of the sections: behavior, preference, and knowledge).

One hundred and eighty-seven children completed food diaries. The intervention children's consumption of fruit and vegetables increased, and they consumed fewer salty snacks after the program. Rural children were confirmed to have healthier diets at baseline. Furthermore, Hirvonen et al., (2017) reported that the great impact of caregivers' nutrition knowledge and its complementarity with market access and better nutrition knowledge leads to considerable improvements in Dietary diversity in adolescents, but only in areas with good market access. Our results show that policymakers and implementer programmers need to ensure that nutritional knowledge improvements are supplemented with improvements in food access. 
Table (3): Differences between the mean scores of mothers and their children" control\& experimental "groups on questionnaire survey about Nutrition assessing Knowledge in post application

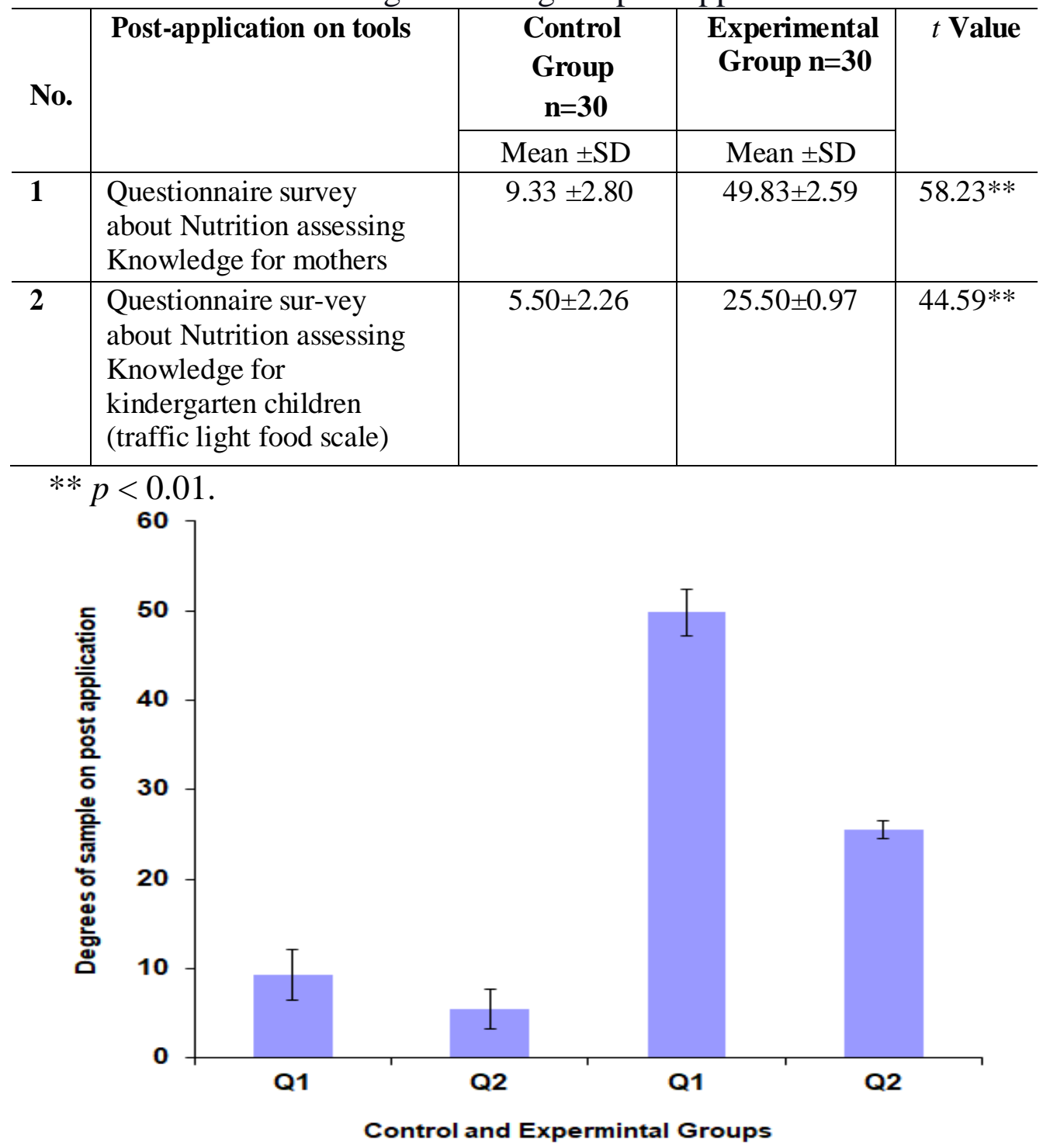

Figure 2. Differences between the mean scores (Mean $\pm \mathrm{SD}$ ) of mothers and their children" control and experimental "groups on Questionnaire survey about Nutrition assessing Knowledge in post application. 
Differences between the mean scores of children in" control\& experimental "groups on the questionnaire of traumatic disorder during the COVID 19 pandemic in the post-application

The total score of kindergarten children in post-application on the Questionnaire survey about Trauma Symptoms during COVID19 pandemic for kindergarten children is in the Table (4),Figure (3) the results showed that there are statistically significant differences between the mean scores of kindergarten children of the control group (46.33 \pm 5.14$)$ and the mean scores of kindergarten children of the experimental group $(92.50 \pm 4.58)$ on the questionnaire survey about Trauma Symptoms during COVID19 pandemic for kindergarten children in the post-application, as indicated by the mean total scores of $t$ value $=36.7340$ and $p<0$. 01 .

Such data attribute these statistical differences in the dimensional scores of the post-application in the control and experimental groups for nutritional education sessions for children that help thembuild knowledge, skills, attitudes, and positive health behaviors. Nutritional education includes everything related to the health of the body, mind, emotions, and community health. It encourages students to improve and enhance their health and avoid unhealthy habits and behaviors, and thus protect them from diseases, and everything that may harm their health and quality of life. And all of these help them to reduce their symptoms of fear and anxiety for infection with the COVID19 virus. Also left enough time to answer all the mothers 'questions and discuss with them, and to use learning by real and vivid examples. The two researchers also discussed easily and interestingly with the children about what they learned from the sessions. Also, the two researchers' use of the homework method encouraged the sample members to learn, and its continuity and impact. In addition to the method of encouragement and reinforcement, it helped children to achieve and learn and stimulate their motivation to learn. 
In a similar study, Jiao et al., 2020 studied behavioral and emotional disorders in children during the COVID19 epidemic to raise awareness of children's psychological needs during epidemics and to report early data collected in COVID19 affected areas in China during the current outbreak, highlighting the role for families and caregivers in timely and negative emotions recognition and management. And results of the study showed that Children are not indifferent to the dramatic impact of the COVID19 epidemic. They are in fear, uncertainty, and physical and social isolation. For a long time, they may miss school. Recognizing their responses and emotions is extremely important if their needs are to be properly addressed. Also Golberstein et al., 2019 confirmed in their studies that The COVID19 pandemic may get worse existing mental health issues and lead to more cases among school children due to the unique combined effect of the public health problem and social isolation. Furthermore, Shanafelt et al., 2020 found that it is important to understand the sources of their anxiety and fear and provide specific support in healthcare.

Table (4): Differences between the mean scores of children" control\& experimental "groups on the questionnaire of traumatic disorder during the COVID19 pandemic in the post-application

\begin{tabular}{c|l|c|c|c}
\hline \multirow{2}{*}{ No } & $\begin{array}{l}\text { post-applicationon } \\
\text { Tools }\end{array}$ & $\begin{array}{c}\text { Control } \\
\text { Group } \\
\mathbf{n = 3 0}\end{array}$ & $\begin{array}{c}\text { Experimental } \\
\text { Group } \\
\text { N= 30 }\end{array}$ & \multirow{2}{*}{$\boldsymbol{t}$ Value } \\
\cline { 2 - 4 } $\mathbf{1}$ & $\begin{array}{l}\text { Mean } \pm \text { SD } \\
\text { Questionnaire } \\
\text { survey about } \\
\text { Trauma } \\
\text { Symptoms during } \\
\text { COVID19 } \\
\text { Pandemic for } \\
\text { kindergarten children }\end{array}$ & $46.33 \pm 5.14$ & $92.50 \pm 4.58$ & \multirow{2}{*}{$36.7340 * *$} \\
$* * p<0.01$. & & \\
\hline
\end{tabular}




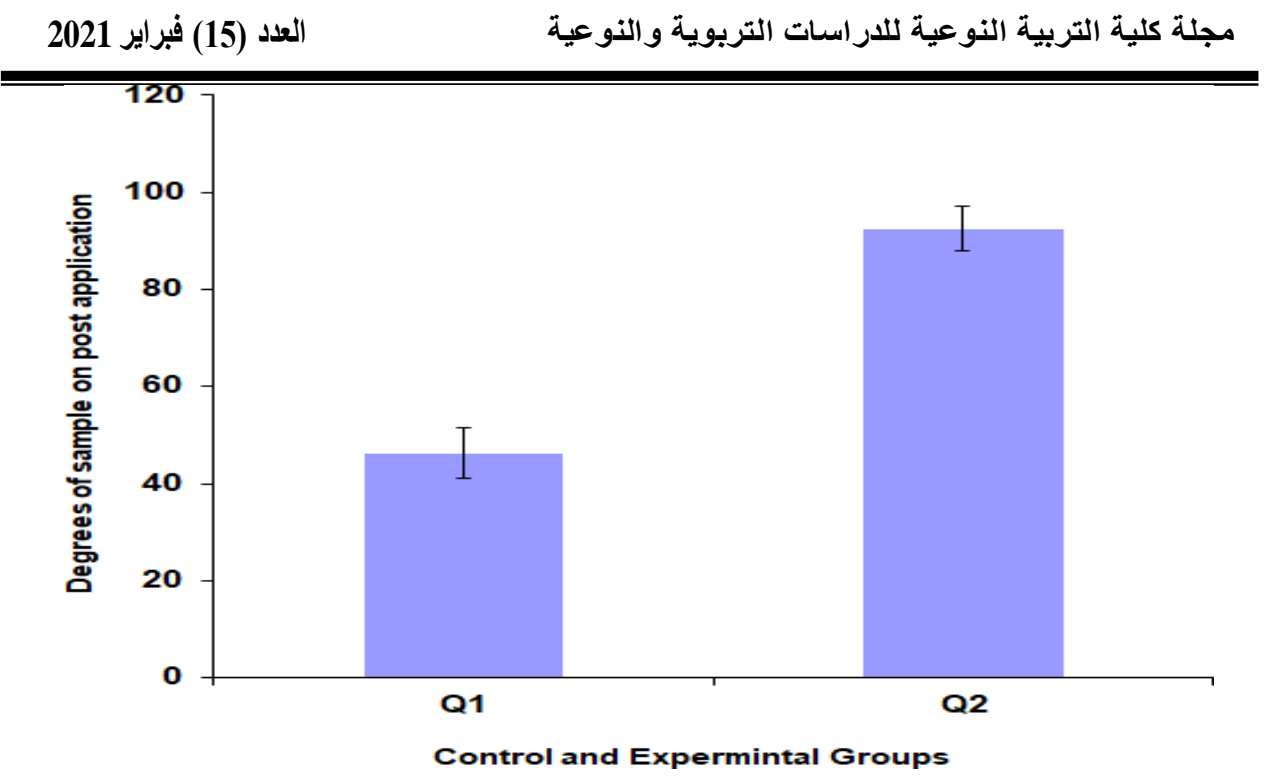

Figure 3. Differences between the mean scores (Mean $\pm \mathrm{SD}$ ) of children" control and experimental "groups on the questionnaire of traumatic disorder during the COVID 19 pandemic in the post-application.

Differences between the mean scores of children in the" experimental "group on Questionnaire survey about Trauma Symptoms during COVID19 Pandemic for kindergarten children inthe pre and post applications.

The total score of kindergarten children on questionnaire survey about Trauma Symptoms during COVID19 Pandemic for kindergarten children in pre and post applications in Tables (5 and 6) and Figure (4) the results showed that there is statistically significant differences between the mean scores of kindergarten children on questionnaire survey about Trauma Symptoms during COVID19 Pandemic for kindergarten children in the pre (52.67 \pm $3.41)$ and post $(92.50 \pm 4.58)$ applications, as indicated by the mean total scores of $(t$ value $=38.2061$ and $p<0.01)$. Also, the Frequency of kindergarten anxiety symptoms showed that The most com- mon anxiety symptoms reported by mothers were: 
Domain 6: Emotions by (-) = 8.5 he/she has to keep thinking special thoughts to stop bad things such as Difficulty controlling emotions, Trouble recognizing emotions, Increased sensitivity to stress, Shame, and guilt, Excessive worry/hopelessness, Feeling of helplessness/lack of self-efficacy. Then, domain 5: Behaviors with $(-)=6.5$ which includes some behavioral doings such as Poor selfregulation, social withdrawal, Aggression, Poor impulse control, Risk-taking, Fear. After that domain 7: Physical Health with (-) $=6.17$ That include (5) negative behaviors show that: Sleep disorder, eating disorder, feeling tired, Poor immune system functioning, Unwillingness to play and move next Domain 1: Relationships with $(-)=5.83$ that show Attachment problems/ disorders, poor understanding of social interactions, Difficulty forming relationships with peers, Problems in relationships, Loss of independence. After that Domain 4: Cognition with (-) 4.67 which includes some behavioral doings such as Impaired read less to learn, Difficulty problem solving, Language delays, Problems with concentration, poor academic achievement. Next Domain 3: Brain Development with $(-)=4.34$ that shows Reduce brain development, less efficient processing, Impaired stress response, Changes in expression. Finally, Domain 2: Mental Health with $(-)=3.83$ which includes some behavioral doings such as Depression, Anxiety, Negative self-image / low self-concept.

Such data showed that the severity of trauma symptoms in children can be reduced by health knowledge, which is one of its practices in nutritional knowledge, as mothers' knowledge that proper, balanced and varied food with nutritional value improves children's immunity and makes them able to resist the virus by being resistant to negative feelings, whether on the psychological level, which includes less efficient processing, feeling of helplessness/lack of self-efficacy, difficulty controlling emotions, problems in relationships and problems with concentration or at the physical level, which includes sleep disorder, eating disorder, feeling tired and poor immune system functioning. and even the cognitive level, 
which includes language delays and poor academic achievement. In a similar study, Ross et al., (2012) confirmed that the role of nutrition in human performance and explained nutritional roles in integrated biologic systems such as nutrient-gene mechanisms and digestive, endocrine, immune, and neural mechanisms also this study confirmed food insecurity in children. Also, Herrin and Larkin (2013) confirmed that the effective role of Nutrition counseling for Individuals with a diagnosis of anxiety, depression, post-traumatic stress disorder (PTSD). Furthermore, Shalev et al., (2012) found that context preventing posttraumatic stress disorder (PTSD) byearly treatment is a pressing public health need.

Table (5). Differences between the mean scores of children in the experimental group on questionnaire survey about Trauma Symptoms during COVID19 Pandemic for kindergarten children in thepre and post applications.

\begin{tabular}{|c|c|c|c|c|}
\hline \multirow[t]{2}{*}{ No. } & $\begin{array}{c}\text { application on } \\
\text { Tools }\end{array}$ & $\begin{array}{c}\text { Pre application } \\
\text { Experimental } \\
\text { Group } \\
\mathbf{n}=\mathbf{3 0}\end{array}$ & $\begin{array}{c}\text { post application } \\
\text { Experimental } \\
\text { Group } \\
\mathbf{n}=\mathbf{3 0}\end{array}$ & $t$ value \\
\hline & & Mean \pm SD & Mean \pm SD & \\
\hline 1 & $\begin{array}{l}\text { Questionnaire survey } \\
\text { about Trauma } \\
\text { Symptoms during } \\
\text { COVID19 Pandemic } \\
\text { for kindergarten } \\
\text { children }\end{array}$ & $52.67 \pm 3.41$ & $92.50 \pm 4.58$ & $38.2061 * *$ \\
\hline
\end{tabular}


Table (6). Scores of differences between the mean scores of children in the experimental group on the single dimensions of Questionnaire survey about Trauma Symptoms during COVID19 Pandemic for kindergarten children in the pre and post applications.

\begin{tabular}{|c|c|c|c|c|c|}
\hline No. & Domains & Group & M1 & M2 & $(-)$ \\
\hline 1 & Domain 1: Relationships & \multirow{7}{*}{ 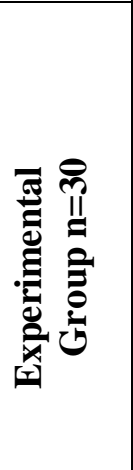 } & 7.00 & 12.83 & 5.83 \\
\hline 2 & Domain 2: Mental Health & & 3.50 & 7.33 & 3.83 \\
\hline 3 & Domain 3: Brain Development & & 6.33 & 10.67 & 4.34 \\
\hline 4 & Domain 4: Cognition & & 9.33 & 14.00 & 4.67 \\
\hline 5 & Domain 5: Behaviors & & 10.50 & 17.00 & 6.5 \\
\hline 6 & Domain 6: Emotions & & 8.67 & 17.17 & 8.5 \\
\hline 7 & Domain7: Physical Health & & 7.33 & 13.50 & 6.17 \\
\hline
\end{tabular}

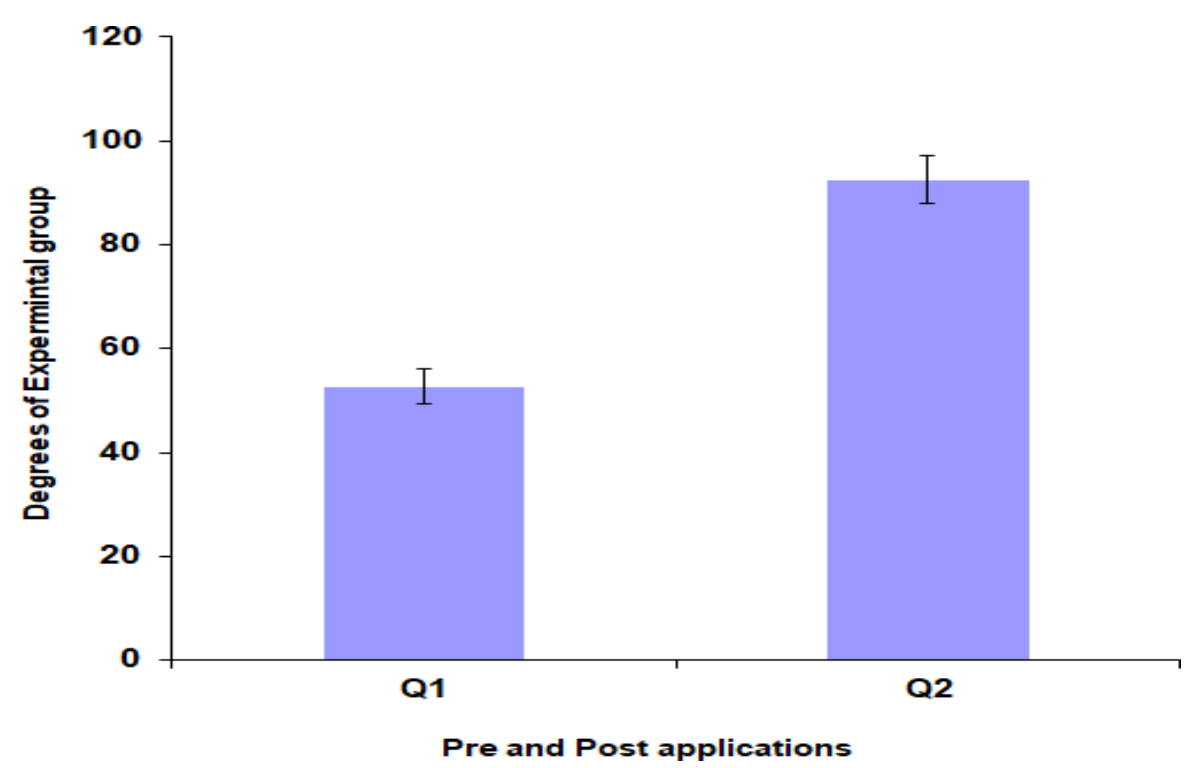

Figure 4. Differences between the mean scores (Mean $\pm \mathrm{SD}$ ) of children in the experimental group on Questionnaire survey about Trauma Symptoms during COVID19 Pandemic for kindergarten children in the pre and post applications. 
Effect of nutritional knowledge in alleviating the severity of trauma symptoms on kindergarten children during the COVID 19 pandemic

Results showed that there were a significant association between total traumatic Disorder events reported by children mothers and nutrition knowledge education course during COVID19 pandemic totally $(r=0.873, p=0.01)$, separation Domain 1: Relationships $(r=0.88, p=0.01)$, separation Domain 2: Mental Health $(r=0.80, p=0.01)$, separation Domain 3: Brain Development ( $r=0.82, p=0.01)$, separation Domain 4: Cognition $(r=0.87, p=0.01)$, separation Domain 5: Behaviors $(r=0.86, p=0.01)$, separation Domain 6: Emotions $(r=0.93, p=0.01)$, and separation Domain7: Physical Health $(r=0.90, p=0.01)$. In a similar study, Mollica et al, (1993) reviewed the long-term effects of trauma and confinement on the functioning and mental health status of Cambodian displaced people living on the Thai-Cambodia border. The study found that 25 percent reported lack of food or water and 5 percentto 10 percent reported significant injury, combat, and shelling. More than 80 percent said that they were poor or fair, felt depressed, and had some somatic symptoms despite good access to healthcare care.

\section{Conclusion}

The present study shows that mothers can pass Awareness to their young children about safe foods. This will assist to lead in childhood to healthy food choices later. Also, this study identified the necessity for nutrition knowledge education courses, paying attention to abnormal psychological behaviors in children, finding out their causes, and trying to find solutions that may contribute to preventing their emergence in children. Additionally, paying attention toward educating mothers, assessing their state of knowledge and cultural background on food knowledge, updating it constantly, and discussing everything new will be needed. We recommended searching for new approaches, learning, and training strategies to reduce their emerging psychological disorders, especially in light of the COVID19 pandemic. 


\section{Acknowledgments}

The authors acknowledge the assistance and comments of Prof. Dr. Yousif Elhassaneen, Head Department of Nutrition and Food Science, Faculty of Home Economics, Minoufiya University, Shebin El-Kom, Egypt.

\section{References:}

Al-Majed, I., Murray, J. J., \& Maguire, A. (2001). Prevalence of dentaltrauma in 5-6-and 12-14-year-old boys in Riyadh, Saudi Arabia. DentalTraumatology,17(4), 153-158.

Alshehri, F. S., Alatawi, Y., Alghamdi, B. S., Alhifany, A. A., \& Alharbi, A. (2020). Prevalence of post-traumatic stress disorder during theCOVID-19 pandemicin Saudi Arabia. Saudi Pharmaceutical Journal, 28(12), 1666-1673.

Amahmid, O.; El Guamri, Y.; Rakibi, Y.; Yazidi, M.; Razoki, B.; Kaid Rassou, K., and Belghyti, D. (2020). Nutrition education in school curriculum: impact on adolescents' attitudes and dietary behaviors. International Journal of Health Promotion and Education, 58(5), 242-258.

Assari, S. (2020). Family socioeconomic status and exposure to childhood trauma: Racial differences. Children, 7(6), 57.

Bataineh, M. F., and Attlee, A. (2020). Reliability and validity Of Arabic version of revised general nutrition knowledge questionnaire on university students. Public health nutrition, 110.

Centers for Disease Control and Prevention. Covid19 Disease 2019 (COVID-19): How to Protect Yourself \& Others. 2020 April 24 [cited 10 June 2020]. Available from: https://www.cdc.gov/covid19/2019-ncov/preventgetting-sick/prevention.html.

Dalton, L.; Rapa, E., and Stein, A. (2020). Protecting the psychological health of children through effective communication about COVID-19. The Lancet Child \& Adolescent Health, 4(5), 346-347. 
de Miranda, D. M., da Silva Athanasio, B., de Sena Oliveira, A. C., \& Silva, A. C. S. (2020). How is COVID-19 pandemic impacting mental health of children and adolescents?.

International Journal of Disaster Risk Reduction:IJDRR, 51, 101845.

El-Khodary, B., and Samara, M. (2020). The relationship between multiple exposures to violence and war trauma, and mental health and behavioral problems among Palestinian children and adolescents. European child \& adolescent psychiatry, 29(5), 719-731.

Fadare, O.; Amare, M.; Mavrotas, G.; Akerele, D., and Ogunniyi, A. (2019). Mother's nutrition-related knowledge and child nutrition outcomes: Empirical evidence from Nigeria. PloS one, 14(2), e0212775.

Feldman, R., and Vengrober, A. (2011). Posttraumatic stress disorder in infants and young children exposed to war related trauma. Journal of the American Academy of Child \& Adolescent Psychiatry, 50(7), 645-658.

Fisberg, M., and Batista, L. D. (2020). Nutrition Related-Practices in Brazilian Kindergarteners: Identifying Challenges and Addressing Barriers. Building Future Health and Well-Being of Thriving Toddlers and Young Children, 95, 1-10.

Friel, S.; Kelleher, C.; Campbell, P., and Nolan, G. (1999). Evaluation of the nutrition education at primary school (NEAPS) programmer. Public health nutrition, 2(4), 549-555.

Golberstein, E.; Gonzales, G., and Meara, E. (2019). How do economic downturns affect the mental health of children? evidence from the National Health Interview Survey. Health Econ;28(8):955-970. doi:10.1002/hec.3885.

Gower, J. R.; Moyer-Mileur, L. J.; Wilkinson, R. D.; Slater, H., and Jordan, K. C. (2010). Validity and reliability of a nutrition knowledge survey for assessment in elementary school children. Journal of the American Dietetic Association, 110(3), 452-456. 
Gurwitch, R. H.; Salem, H.; Nelson, M. M., and Comer, J. S.(2020). Leveraging parent-child interaction therapy and tele- health capacities to address the unique needs of young children during the COVID-19 public health crisis. Psychological Trauma: Theory, Research, Practice, and Policy, 12(S1), S82S84.

Health, E.M. [COVID-19 status in Egypt] (2020). Available from: https://www.care.gov.eg/EgyptCare/Index.aspx . Accessed 5 May, 2020.

Herrin, M., and Larkin, M. (2013). Nutrition counseling in the treatment of eating disorders. Routledge.

Hirvonen, K.; Hoddinott, J.; Minten, B., and Stifel, D. (2017). Children's diets, nutrition knowledge, and access to markets. World Development, 95, 303-315.

Jacka, F. N.; Ystrom, E.; Brantsaeter, A. L.; Karevold, E.; Roth, C.; Haugen, M., and Berk, M. (2013). Maternal and early postnatal nutrition and mental health of offspring by age 5 years: a prospective cohort study. Journal of the American Academy of Child \& Adolescent Psychiatry, 52(10), 1038-1047.

Jiao, W. Y.; Wang, L. N.; Liu, J.; Fang, S. F.; Jiao, F. Y.; PettoelloMantovani, M., and Somekh, E. (2020). Behavioral and emotional disorders in children during the COVID-19 epidemic. The journal of Pediatrics, 221, 264.

Johns Hopkins University. (2020) Covid19 Resource Center. [cited 28 September 2020]. Available from: https://covid19.jhu.edu/map.html.

Johnson, M. (2017). Design and Validation of a Scale for Preschoolers: Measuring Nutrition Knowledge, Beliefs, and Behaviors (Doctoral dissertation, East Tennessee State University), 3332.

Khalid, S.; Williams, C. M., and Reynolds, S. A. (2016). Is there an association between diet and depression in children and adolescents? A systematic review. British journal of nutrition, 116(12), 2097-2108. 
Kliemann, N.; Wardle, J.; Johnson, F., and Croker, H. (2016). Reliability and validity of a revised version of the General Nutrition Knowledge Questionnaire. European journal of clinical nutrition, 70(10), 1174-1180.

Konstantopoulou, G.; Pantazopoulou, S., and Iliou, T. (2020). Detection of post-traumatic stress disorder (PTSD) symptoms associated with Covid19 disease 2019 (COVID-19) in the student population. European Journal of Special Education Re-search, 6(3).

Lassale, C.; Batty, G. D.; Baghdadli, A.; Jacka, F.; SánchezVillegas, A.; Kivimäki, M., and Akbaraly, T. (2019). Healthy dietary indices and risk of depressive outcomes: a systematic review and meta-analysis of observational studies. Molecular psychiatry, 24(7), 965-986.

Malarbi, S.; Abu-Rayya, H. M.; Muscara, F., and Stargatt, R. (2017). Neuropsychological functioning of childhood trauma and posttraumatic stress disorder: A meta-analysis. Neuroscience \& Bio behavioral Reviews, 72, 68-86.

Masten, C. L.; Guyer, A. E.; Hodgdon, H. B.; McClure, E. B.; Charney, D. S.; Ernst, M., and Monk, C. S. (2008). Recognition of facial emotions among maltreated children with high rates of post-traumatic stress disorder. Child abuse \& neglect, 32(1), 139-153.

Mollica, R. F.; Donelan, K.; Tor, S.; Lavelle, J.; Elias, C.; Frankel, M., and Blendon, R. J. (1993). The effect of trauma and confinement on functional health and mental health status of Cambodians living in Thailand-Cambodia border camps. Jama, 270(5), 581-586.

Nekitsing, C.; Hetherington, M. M., and Blundell-Birtill, P. (2018). Developing healthy food preferences in kindergarten children through taste exposure, sensory learning, and nutrition education. Current obesity reports, 7(1), 60-67.

Orgilés, M.; Morales, A.; Delvecchio, E.; Mazzeschi, C., and Espada, J. P. (2020). Immediate psychological effects of the 
COVID-19 quarantine in youth from Italy and Spain. Frontiers in psychology, 11, 2986.

Pat-Horenczyk, R.; Cohen, S.; Ziv, Y.; Achituv, M.; Asulin-Peretz, L.; Blanchard, T. R., and Brom, D. (2015). Emotion regulation in mothers and young children faced with trauma. Infant mental health journal, 36(3), 337-348.

Perez L. (2018). The Role of Dietary Patterns in Mood Disorders: Prospective Research in Youth Populations. American journal of lifestyle medicine, 12(4), 286-290.

Phelps, C., and Sperry, L. L. (2020). Children and the COVID-19 pandemic. Psychological Trauma: Theory, Research, Practice, and Policy, 12(S1), S73.

Rapson, J.; Conlon, C., and Ali, A. (2020). Nutrition Knowledge and Perspectives of Physical Activity for Pre-Scholars amongst Early Childhood Education and Care Teachers. Nutrients, 12(7), 1984.

Ross, A. C.; Caballero, B.; Cousins, R. J.; Tucker, K. L., and Ziegler, T. R. (2012). Modern nutrition in health and disease (No. Ed. 11). Lippincott Williams \& Wilkins.

Scheeringa, M. S.; Weems, C. F.; Cohen, J. A.; Amaya-Jackson, L., and Guthrie, D. (2011). Trauma-focused cognitive-behavioral therapy for posttraumatic stress disorder in three-through six year-old children: A randomized clinical trial. Journal of Child Psychology and Psychiatry, 52(8), 853-860.

Schiff, M.; Pat-Horenczyk, R.; Ziv, Y., and Brom, D. (2017). Multiple traumas, maternal depression, mother-child relationship, social support, and young children's behavioral problems. Journal of interpersonal violence, 0886260517725738-88.

Shalev, A. Y.; Ankri, Y.; Israeli-Shalev, Y.; Peleg, T.; Adessky, R., and Freedman, S. (2012). Prevention of posttraumatic stress disorder by early treatment: results from the Jerusalem Trauma Outreach and Prevention study. Archives of general psychiatry, 69(2), 166-176. 
Shanafelt, T.; Ripp, J., and Trockel, M. (2020). Understanding and addressing sources of anxiety among health care professionals during the COVID-19 pandemic. Jama, 323(21), 2133-2134.

Spinelli, M.; Lionetti, F.; Pastore, M., and Fasolo, M. (2020). Mothers' stress and children's psychological problems in families facing the COVID-19 outbreak in Italy. Frontier in Psychology, 11,1713.

The Arab Republic of Egypt the Prime Minister (2020). [homepage on the Internet]: Available from: https://www.care.gov.eg/EgyptCare /News/Preview .aspx?id= 15059. Accessed 13 March, 2020.

Wang, C.; Pan, R.; Wan, X.; Tan, Y.; Xu, L.; McIntyre, R. S.; Choo, F. N.; Tran, B.; Ho, R.; Sharma, V. K., and Ho, C. (2020). A longitudinal study on the mental health of general population during the COVID-19 epidemic in China. Brain, Behavior, and Immunity, 87, 40-48.

Wilson, J. P., and Tang, C. C. S. K. (Eds.). (2007). Cross-cultural assessment of psychological trauma and PTSD. Springer Science \& Business Media.

Woolgar, F. (2020). The psychological impact of trauma on preschool children and their parents (Doctoral dissertation of Clinical Psychology. University of East Anglia). Faculty of Medicine and Health Sciences.p14

World Health Organization. WHO (2020). Covid19 disease (COVID-19) pandemic. Retrieved from: https://www.who.int/emergencies/diseases/ novel-covid192019

World meter [website]. COVID-19 coronavirus pandemic. https://www.worldometers.info/coronavirus/?utm_campaign= homeAdvegas 1?\%22 (viewed Jan 2021).

Xiao, H.; Zhang, Y.; Kong, D.; Li, S., and Yang, N. (2020). The effects of social support on sleep quality of medical staff treating patients with covid19 disease 2019 (COVID-19) in January and February 2020 in China. Medical science monitor: 
العدل (15) فبراير 2021 مجلة كلية التربية النوعية للار اسات التربوية و النوعية

Yousafzai, A. K.; Rasheed, M. A., and Bhutta, Z. A. (2013). Annual Research Review: Improved nutrition--pathway to resilience. Journal of child psychology and psychiatry, and allied disciplines, 54(4), 367-377.

Zyśk, B.; Stefańska, E., and Ostrowska, L. (2020). Effect of dietary components and nutritional status on the development of preschool children. Roczniki Panstwowego Zakladu Higieny, 71(4), 393-403. 